\title{
Evaluation efficiency of Iranian natural zeolites and synthetic resin to removal of lead ions from aqueous solutions
}

\author{
Malihe Moazeni $^{1} \cdot$ Saeed Parastar ${ }^{2} \cdot$ Mokhtar Mahdavi $^{3} \cdot$ Afshin Ebrahimi $^{4,5}$ D
}

Received: 27 December 2018 / Accepted: 26 December 2019 / Published online: 24 January 2020

(c) The Author(s) 2020

\begin{abstract}
Heavy metal such as $\mathrm{Pb}^{2+}$ (lead ions) has high toxicity potential, and it can be dangerous for public health and environment. The ion exchange process is one of the methods that can be used for $\mathrm{Pb}^{2+}$ removal from aqueous solutions. The aim of this study was to investigate the removal efficiency of $\mathrm{Pb}^{2+}$ from the synthetic aqueous solutions using Iranian natural zeolite (INZ) (Clinoptilolite) in comparison with a synthetic resin (SR). In this study, the removal of $\mathrm{Pb}^{2+}$ from aqueous solution investigated by INZ and synthetic resin under different experimental conditions. Parameters like initial $\mathrm{Pb}^{2+}$ concentration, contact times, adsorbent dosage, $\mathrm{pH}$ and size particles of INZ, and best-fitted isotherm were studied. The results showed that the most removal efficiency of $\mathrm{Pb}^{2+}$ with INZ was obtained at $\mathrm{pH} 3-5$, contact time 15-60 min, adsorbent dosage 20-50 g/L, $\mathrm{Pb}^{2+}$ initial concentration $25 \mathrm{mg} / \mathrm{L}$, and the removal efficiency was increased with decreasing INZ particle size. The high removal of $\mathrm{Pb}^{2+}$ with SR was at $\mathrm{pH} 4-6$, for $25 \mathrm{mg} / \mathrm{L}$ initial $\mathrm{Pb}^{2+}$ concentration at $15-60 \mathrm{~min}$ and 5-10 $\mathrm{g} / \mathrm{L}$ SR. Isotherms study with ISOFT software indicates that the Freundlich and Langmuir isotherms expression provides the best fit for $\mathrm{Pb}^{2+}$ sorption by INZ and SR, respectively. This study indicated that for $\mathrm{Pb}^{2+}$ ion removal, the SR was more efficient than INZ for high concentration solutions; however, in low concentration of $\mathrm{Pb}^{2+}$, the removal efficiency was approximately equal.
\end{abstract}

Keywords Lead ions · Aqueous solutions $\cdot$ Synthetic resin $\cdot$ Iranian natural zeolites (INZ) · Adsorption isotherm

\section{Introduction}

Worldwide developments, population growth, and industrialization have caused the accumulation of $\mathrm{Pb}^{2+}$ to the formation of enormous volumes of wastes and environmental

Afshin Ebrahimi

a_ebrahimi@hlth.mui.ac.ir

1 Student Research Committee, School of Health, Isfahan University of Medical Sciences, Isfahan, Iran

2 Department of Environmental Health Engineering, School of Health, Ardabil University of Medical Sciences, Ardabil, Iran

3 Department of Environmental Health Engineering, Social Determinants of Health Research Center, Saveh University of Medical Sciences, Saveh, Iran

4 Department of Environmental Health Engineering, School of Health, Isfahan University of Medical Sciences, Isfahan, Iran

5 Environment Research Center, Research Institute for Primordial Prevention of Non-communicable Disease, Isfahan University of Medical Sciences, Isfahan, Iran pollution (Mahdavi et al. 2017). Special industrial wastes from mining, electroplating, $\mathrm{Pb}^{2+}$ smelting, and metal finishing industries discharge substantial amounts of heavy metals (Abdel-Halim et al. 2003; Inglezakis et al. 2002) such as mercury, chromium, nickel, copper, zinc, cadmium and $\mathrm{Pb}^{2+}$ into water resources that are hazardous for the public health, ecosystem, and environment (Kim et al. 2013). Heavy metals are not biodegradable and have a tendency to accumulate in organisms, causing various diseases and disorders (Inglezakis et al. 2003; Mozgawa et al. 2009). Therefore, it is necessary to remove this material before entering the environment. $\mathrm{Pb}^{2+}$ is one of the materials that have adverse effects on public health (Moazeni et al. 2017).

Chemical treatment, ion exchange, precipitation, filtration, oxidation-reduction, electrochemical recovery, ultrafiltration, reverse osmosis, electrodialysis, and adsorption are being used to remove such metals from water resources (Mier et al. 2001). However, many of these approaches may be ineffective, too expensive, or not easy to apply in developing countries. Hence, ion exchange is considered to be cost-effective if low-cost ion exchangers such as zeolites are used (Hesami et al. 2013). In this regard, the availability 
of naturally occurring zeolites in many countries provides low-cost treatment by ion exchange systems to remove heavy metals from industrial wastewater. The main advantages of ion exchange over chemical precipitation are the recovery of metal amounts, selectivity, less sludge volume production, and the meeting of stringent discharge specifications (Ali and El Bishtawi 1997).

Zeolites are a large family of crystalline hydrated aluminosilicates that have unique properties like anions and cations exchangeability (Jha et al. 2008; Mozgawa et al. 2009). Among more than 40 natural zeolites, Clinoptilolite is the most abundant that most often used water and wastewater treatment (Barrera-Diaz et al. 2005; Berber-Mendoza et al. 2006; Calvo et al. 2009; Faghihian et al. 1999; Hamidpour et al. 2010; Hwang et al. 2011; Suh and Kim 2000; Yang et al. 2011). Consistent amounts of this zeolite type are found in volcanic tuffs in different parts of Iran. The zeolite grade, in most cases, is higher than $90 \%$ and can reach about 95\% (Faghihian et al. 1999). Heavy metals removal by this material is based on the cationic exchanges between heavy metals and cations, such as sodium and potassium or the precipitation of heavy metal hydroxides over the zeolite external surfaces (Castaldi et al. 2008). Based on this, the aim of the present study was to investigate the removal efficiency of $\mathrm{Pb}^{2+}$ from the synthetic aqueous solutions using Iranian natural zeolite (INZ) (Clinoptilolite) in comparison with a synthetic resin type. Some parameters like the effect of solution $\mathrm{pH}$ on $\mathrm{Pb}^{2+}$ adsorption, contact time, the initial concentration of $\mathrm{Pb}^{2+}$, adsorbent dosage, particle size of INZ, and adsorption isotherms were studied.

\section{Materials and methods}

\section{Instruments}

$\mathrm{Pb}^{2+}$ analyses were carried out using a flame atomic absorption instrument (PerkinElmer model 2380). A reciprocating shaker was used to agitate the mixtures at room temperature. A Metrohm pH meter model 525A was used for $\mathrm{pH}$ measurements. Particle sizes of the INZ samples were determined using a series of laboratory sieves in several meshes.

\section{Reagents and solutions}

All the chemicals used were of analytical reagent grade. Deionized water was used throughout the experimental studies. Lead nitrate $\left(\mathrm{Pb}\left(\mathrm{NO}_{3}\right)_{2}\right), \mathrm{HCl}$, and $\mathrm{NaOH}$ were purchased from Merck (Darmstadt, Germany), the representative seller in Iran. A $1 \mathrm{~g} / \mathrm{L}$ concentration of $\mathrm{Pb}^{2+}$ solutions was prepared and stored for a short time until test implementation.

\section{Adsorbent compounds}

Iranian natural zeolite (INZ), Clinoptilolite, was supplied by the Afrand Tooska Co. in Iran under the trade name of Anzymite. These zeolites were extracted from Semnan mines in the northeast of Iran (Sharghe Haftdareh). In this location, zeolite deposits are found in some horizons of sedimentary volcanic rocks, which were dependent on Eocene. These deposits were situated in anticline structure with a gentle slope, about $10^{\circ}-15^{\circ}$. The level of utilization of these deposits is widespread in Iran. In some locations, the thickness of zeolite horizons is greater than $20 \mathrm{~m}$. These types of zeolite deposit are Clinoptilolite as well as quartz, halite, sodium sulfate, glubrite, tenardite, and also crystobalite. The position of this mine is illustrated in Fig. 1. An English Purolite strong acid cation exchanger was also purchased and was used as SR. The Anzymite (natural zeolite) and synthetic resin (Purolite) properties which were obtained from manufacturers are shown in Tables 1 and 2.

\section{Preparation of INZ samples}

To achieve the desired particle size, INZ prepared using different laboratory meshes, to lie in three sieve granulation sizes (> 1180, 420-1180, and 297-420 $\mu \mathrm{m}$ ). A 420-1180$\mu \mathrm{m}$ grading class was used as major grade, and two other classifications were used to determine the effects of particle size on ion exchange capacity of INZ. Then, for eliminating of very fine dust particles, the INZ samples were washed with deionized water, repeatedly, and in order to their increase the cation exchange capacity, $10 \mathrm{~g}$ of INZ was placed in reflux ( $358 \mathrm{~K}$ ) with $200 \mathrm{~mL} 1 \mathrm{M} \mathrm{NaCl}$ solutions for $48 \mathrm{~h}$, and then the phases were separated. The materials were rinsed with deionized water several times again, to achieve $\mathrm{a} \mathrm{Cl}^{-}$-free solution and were tested using silver nitrate solution as an indicator. The resultant materials after drying in laboratory air were dried at $110{ }^{\circ} \mathrm{C}$ for $24 \mathrm{~h}$ and were kept under a desiccator until the experiment was done.

\section{Adsorption procedures}

One at the time technique was used for the sorption experiments by a batch technique at room temperature, and all tests were triplicates (Fig. 2). To compare the results in each series of tests, one blank sample also was considered. To study $\mathrm{Pb}^{2+}$ sorption, start by an accurate weight of $1.5 \mathrm{~g}$ $(30 \mathrm{~g} / \mathrm{L})$ of this type of zeolite and $0.5 \mathrm{~g}(10 \mathrm{~g} / \mathrm{L})$ of SR which were shaken with $50 \mathrm{~mL}$ of $25,50,100,150,200$, and $250 \mathrm{mg} / \mathrm{L} \mathrm{Pb}^{2+}$ solutions for $120 \mathrm{~min}$ at constant $\mathrm{pH} 4.5$ (asbuilt $\mathrm{pH}$ of synthetic aqueous solutions), laboratory temperature and with 160 times the reciprocating speed of shaker, separately. Thereinafter to survey of adsorbent dose changes 


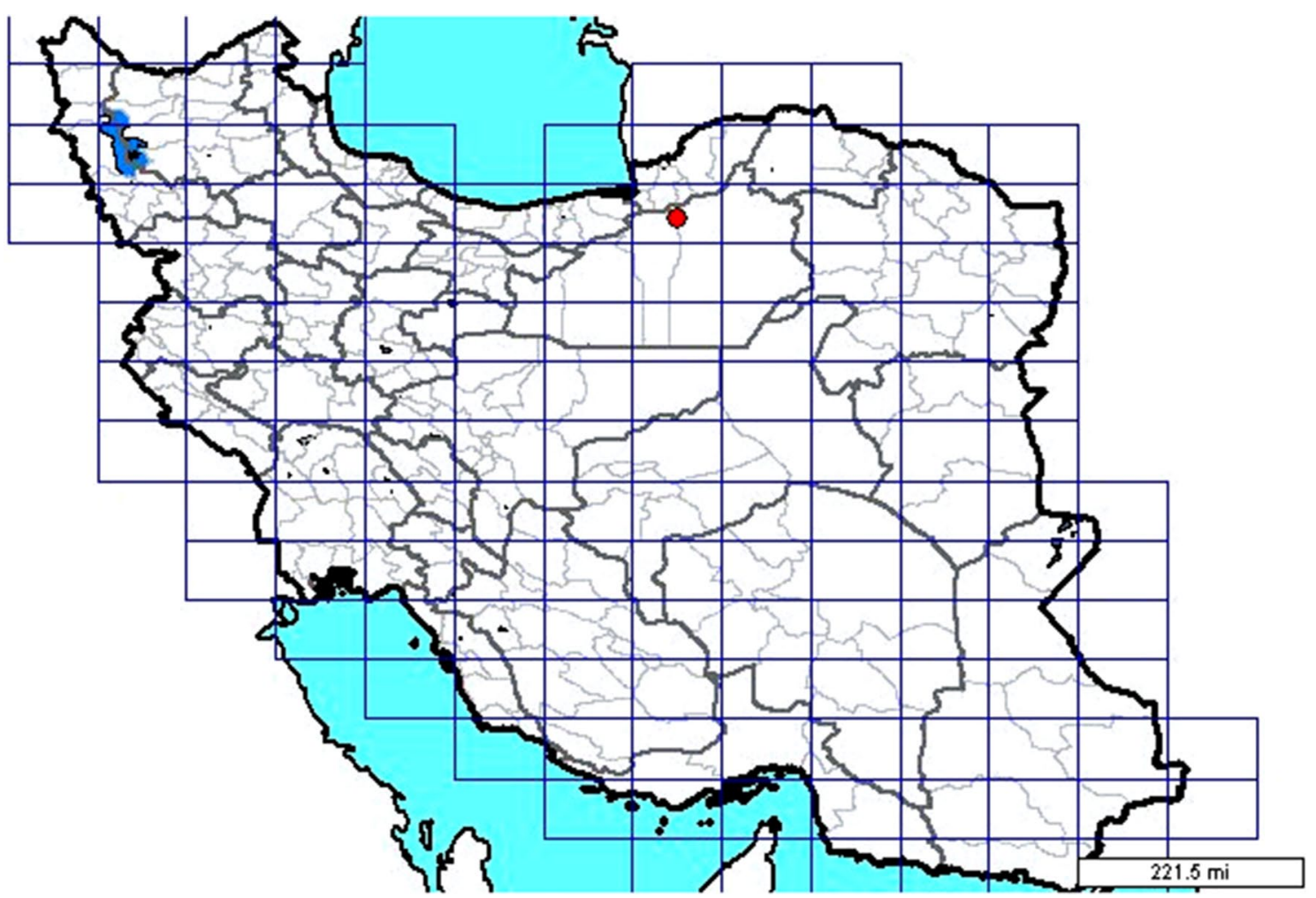

Fig. 1 Semnan mines in the northeast of Iran (Sharghe Haftdareh)

Table 1 Chemical and physical properties of Anzymite

\begin{tabular}{ll}
\hline & Percent (\%) in $100 \mathrm{~g}^{\mathrm{a}}$ \\
\hline Chemical properties & \\
$\mathrm{SiO}_{2}$ & 66.5 \\
$\mathrm{Al}_{2} \mathrm{O}_{3}$ & 11.8 \\
$\mathrm{CaO}$ & 3.1 \\
$\mathrm{~K}_{2} \mathrm{O}$ & 2.1 \\
$\mathrm{Na}_{2} \mathrm{O}$ & 2 \\
$\mathrm{Fe}_{2} \mathrm{O}_{3}$ & 1.3 \\
$\mathrm{MgO}$ & 0.8 \\
$\mathrm{TiO}_{\mathrm{MnO}}$ & 0.3 \\
$\mathrm{MnO}$ & 0.04 \\
$\mathrm{P}_{2} \mathrm{O}_{5}$ & 0.01 \\
Physical properties & \\
Color & Light green \\
CEC in meq/100 g & $160-180$ \\
Specific gravity in $\left(\mathrm{g} / \mathrm{cm}^{3}\right)$ & 1 \\
Mineral percent $(\%)$ & $85-95$ \\
Cations adsorption selectivity & $\mathrm{Cs}>\mathrm{Rb}>\mathrm{K}>\mathrm{NH}{ }_{4}>\mathrm{Ba}>$ \\
& $\mathrm{Sr}>\mathrm{a}>\mathrm{Ca}>\mathrm{Fe}>\mathrm{Al}>\mathrm{M}$ \\
& $\mathrm{g}>\mathrm{Li}$ \\
\hline
\end{tabular}

${ }^{a}$ Remainder including of other impurities that were not analyzed on $\mathrm{Pb}^{2+}$ sorption, accurate weights of $1,1.5,2$, and $2.5 \mathrm{~g}(20$, 30,40 and $50 \mathrm{~g} / \mathrm{L}$ ) of zeolite with $50 \mathrm{~mL}$ of $50 \mathrm{mg} / \mathrm{L} \mathrm{Pb}^{2+}$ solutions and $0.25,0.5$, and $0.75 \mathrm{~g}(5,10$ and $15 \mathrm{~g} / \mathrm{L})$ of SR with $50 \mathrm{~mL}$ of $250 \mathrm{mg} / \mathrm{L} \mathrm{Pb}^{2+}$ solutions and with fixed other conditions as above mentioned, were contacted, separately. The influences of solution $\mathrm{pH}$ changes were also examined by $\mathrm{pH}$ range of $3,4,5,6$, and 7 , respectively. With respect to the determination of contact time impacts on adsorption phenomenon, series of tests were also implemented in the range of $1-3.5 \mathrm{~h}$ with 0.5 -h intervals. Finally, an aliquot of the solution was then filtered and $\mathrm{Pb}^{2+}$ concentration in the supernatant was measured by a flame atomic absorption spectroscopy according to the standard method (APHA 2013). Blank solutions were treated similarly and the final concentrations were taken as the initial ones. For the efficiency removal calculation, the following equation was used:

Removal efficiency $=\left[\left(C_{0}-C_{\mathrm{t}}\right) / C_{0}\right] \times 100$

where $C_{0}$ and $C_{\mathrm{t}}(\mathrm{mg} / \mathrm{L})$ are the initial and the final $\mathrm{Pb}^{2+}$ concentrations.

$\mathrm{Pb}^{2+}$ adsorption isotherm experiments using INZ and SR were implemented under of the optimum conditions. The amounts of adsorbed $\mathrm{Pb}^{2+}$ on the adsorbents $\left(q_{\mathrm{e}}\right.$, $\mathrm{mg} / \mathrm{g}$ ) were calculated as follows: 
Table 2 Chemical and physical properties of synthetic resin

\begin{tabular}{ll}
\hline Properties & \\
\hline Polymer structure & $\begin{array}{l}\text { Polystyrene with devinyl side branches } \\
\text { Transparent spheroid particles }\end{array}$ \\
$\begin{array}{l}\text { Physical and appearance shape } \\
\text { Pperational groups }\end{array}$ & $\mathrm{Na}^{+}$ \\
Ionic shape & $850 \mathrm{~g} / \mathrm{L}$ \\
Approximate weight for carrying & \\
Sieve size range & In wet mode, $16-52 \mathrm{Mesh}$ \\
English standard sieve & In wet mode, $16-50$ Mesh \\
American standard sieve & \\
In wet mode, $16-50 \mathrm{Mesh}$ & $+1.2 \mathrm{~mm}<5 \%$ \\
& $-0.3 \mathrm{~mm}<1 \%$ \\
& $44-48 \%$ \\
Moisture content for $\mathrm{Na}^{+}$shape & 1.29 \\
Special weight for $\mathrm{Na}^{+}$shape in wet mode & \\
Total ion exchange capacity for $\mathrm{Na}^{+}$shape & $2 \mathrm{eq} / \mathrm{lmin}$ \\
In wet mode (volumetric) & $4.5 \mathrm{eq} / \mathrm{kg}$ min \\
In dry mode (weighing) & $\mathrm{Maximum} 150{ }^{\circ} \mathrm{C}$ \\
Operating temperature for $\mathrm{Na}^{+}$shape & $0-14$ \\
Stability in the range of $\mathrm{pH}$ &
\end{tabular}

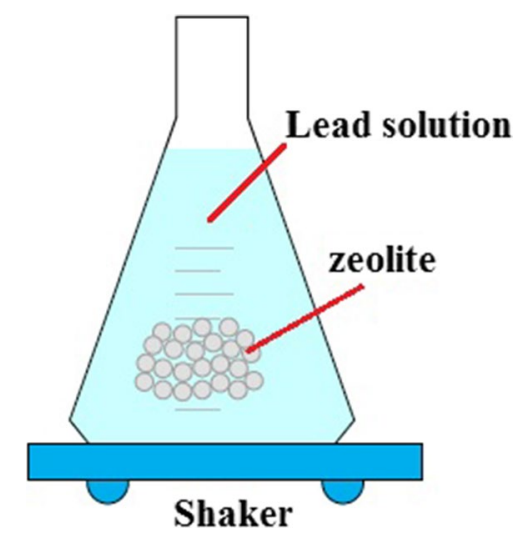

Fig. 2 Scheme of experimental procedure for adsorption study

$q_{\mathrm{e}}=\left(C_{0}-C_{\mathrm{t}}\right) \times \frac{V}{m}$,

where all parameters have defined as the same above at a certain period of time, $V$ is the initial solution volume (L), and $m$ is the adsorbent weight $(\mathrm{g})$.

\section{Analysis of data}

Data analysis was conducted by SPSS 16 software. Isotherm Fitting Tool (ISOFIT) is a software program that fits isotherm parameters to experimental data via the minimization of a weighted sum of squared error (WSSE) objective function. ISOFIT supports a number of isotherms, including (1) Brunauer-Emmett-Teller (BET), (2) Freundlich, (3) Freundlich with linear partitioning (F-P), (4) generalized Langmuir-Freundlich (GLF), (5) Langmuir, (6) Langmuir with linear partitioning (L-P), (7) linear, (8) Polanyi, (9) Polanyi with linear partitioning (P-P), and (10) Toth. Observation weights are ideally assigned according to individual estimates of measurement error, such that $w_{i}=1 / \mathrm{sd}_{i}$, where $\mathrm{sd}_{\mathrm{i}}$ is the standard deviation of the $i$ th measurement.

\section{Results and discussion}

\section{Effect of initial concentration of $\mathrm{Pb}^{2+}$}

The results of the $\mathrm{Pb}^{2+}$ sorption by INZ and $\mathrm{SR}$ at the concentration of $25,50,100,150,200$, and $250 \mathrm{mg} / \mathrm{L}$ are shown in Fig. 3. As shown, the removal efficiency by INZ has been dramatically reduced from 94.48 to $14.24 \%$ with increasing initial $\mathrm{Pb}^{2+}$ concentrations. Performing one-way ANOVA also showed that there was a significant relationship $(p<0.001)$ between $\mathrm{Pb}^{2+}$ removal percentage decrease with the increase in its concentration. For SR, raising $\mathrm{Pb}^{2+}$ concentrations in the range of $25-250 \mathrm{mg} / \mathrm{L}$ had a very low influence on changing its removal efficiency. So, the highest and the lowest removal efficiencies of $99.96 \%$ and $99.4 \%$ were related to $\mathrm{Pb}^{2+}$ concentrations of 25 and $250 \mathrm{mg} / \mathrm{L}$, respectively. In other words, with the increase in $\mathrm{Pb}^{2+}$ concentration, its removal efficiency only lost $0.56 \%$. Then, based on Fig. 3, it can be observed that increase in $\mathrm{Pb}^{2+}$ 


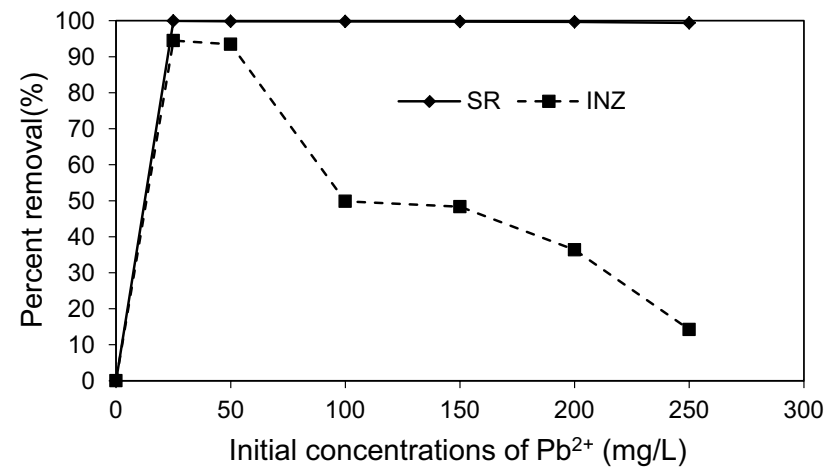

Fig. 3 Removal efficiency of $\mathrm{Pb}^{2+}$ by INZ and SR in several solution concentrations $(\mathrm{pH}=4.5$, contact time $=120 \mathrm{~min}$, adsorbent dose: $\mathrm{INZ}=30 \mathrm{~g} / \mathrm{L}, \mathrm{SR}=10 \mathrm{~g} / \mathrm{L})$

concentrations had no significant impact on the removal decrease trend of SR, but this decreasing trend was significant in INZ. Totally, the initial concentrations of solutions effectively control the performance of ion exchange systems. So as the results of this study and other similar studies, the removal of metal ions by cationic synthetic resin almost does not depend on the initial concentration of solutions, and these compounds show the same behavior in removing metal ions, while increasing the initial concentration of metal ions decreases the efficiency of elimination in natural zeolites (Ulmanu et al. 1996, 2003). Kim et al. (2013) surveyed removal of $\mathrm{Pb}^{2+}$ from aqueous solution by a zeolite-nanoscale zero-valent iron composite, and their results indicated that at the lower concentration $(100 \mathrm{mg} / \mathrm{L}), 99.2 \%$ of the $\mathrm{Pb}^{2+}$ were removed by the Z-nZVI composite. Based on these results, the $\mathrm{Pb}^{2+}$ removal efficiency was decreased when $\mathrm{Pb}^{2+}$ initial concentration increased (Kim et al. 2013).

\section{Effect of contact time}

To study the effect of contact time of INZ and SR on the removal of $\mathrm{Pb}^{2+}$, adsorption conducted at different contact time (Fig. 4). Results showed that the adsorption of the $\mathrm{Pb}^{2+}$ is increased firstly for SR and then constant gradually, while the results were different for INZ. In this study, with respect to technical and economic conditions, the optimal contact time for $\mathrm{Pb}^{2+}$ removal was $60 \mathrm{~min}(1 \mathrm{~h})$. The sorption performance of INZ was low, and it had slight fluctuations during contact times. Final contact time is an important parameter in batch ion exchange processes. According to Donnan membranous phenomenon, the concentration of metal ions in solution always is more than solid phase. So, there was never equilibrium point, and sorption and desorption of metal ions occur especially in low contact times, continuously But, it is an important factor for natural zeolite that has very low exchange kinetics in long contact times, and it can increase the metal removal by these adsorbents.

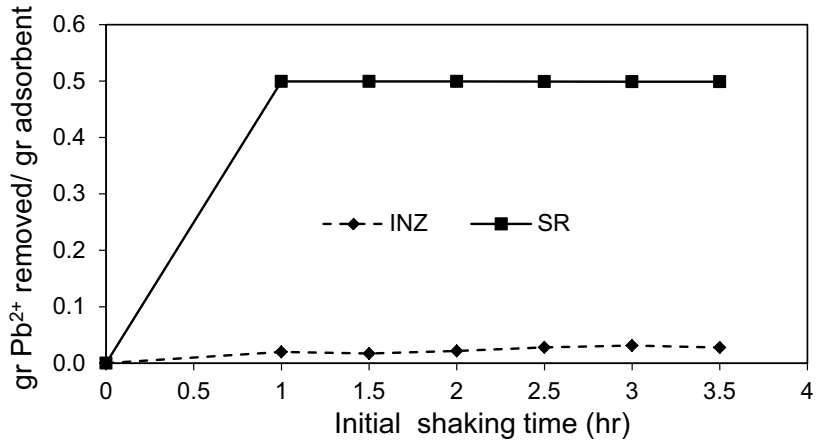

Fig. 4 Effect of contact time on $\mathrm{Pb}^{2+}$ adsorption with INZ and SR $(\mathrm{pH}=4.5$, initial concentration $=50 \mathrm{mg} / \mathrm{L}$, adsorbent dose: $\mathrm{INZ}=30 \mathrm{~g} / \mathrm{L}, \mathrm{SR}=10 \mathrm{~g} / \mathrm{L}$ )

In total, based on results of this study, we can say that contact time 60 min can be suitable for resin exchanger in the removal of $\mathrm{Pb}^{2+}$ from wastewater. Some researchers (Mier et al. 2001; Sawyer et al. 2003) have confirmed our results, and it showed that absorption equilibrium could be accessed in contact times of 18-72 $\mathrm{h}$ only in experimental conditions. Also, they concluded that more than $90 \%$ of the removal has occurred in the first $15 \mathrm{~min}$ of the $24 \mathrm{~h}$ contact time using Clinoptilolite zeolite. Salem and Sene 2011 surveyed removal of $\mathrm{Pb}^{2+}$ from solution by a combination of natural zeolite-kaolin-bentonite, and they reported that amount of $\mathrm{Pb}^{2+}$ adsorption increases with residence time, and it remains relatively constant after about $4 \mathrm{~h}$, reaching equilibrium condition.

\section{Effect of adsorbents dosage}

The effect of adsorbent dosage on $\mathrm{Pb}^{2+}$ removal is presented in Fig. 5. For INZ, with the increase in its dose in the range of $0-50 \mathrm{~g} / \mathrm{L}$, there is more removal observed until a dose of $20 \mathrm{~g} / \mathrm{L}$. Also, for SR with the increase in its dose in the range of $5-15 \mathrm{~g} / \mathrm{L}$, it is observed the same trends but in the lower ranges. One-way ANOVA showed that there was a significant relationship $(p<0.001)$ between $\mathrm{Pb}^{2+}$ ions removal percentage and the increase in both INZ and SR amounts. Based on the Duncan test, it was cleared that the removal percentage increase has a fast trend for $\mathrm{Pb}^{2+}$ in the range of 5-10 g/L resin, but this increasing was lost in the range of $10-15 \mathrm{~g} / \mathrm{L}$. Also, it was observed that with the increasing INZ dosage in the range of $20-50 \mathrm{~g} / \mathrm{L}, \mathrm{Pb}^{2+}$ removal has increased that it was significantly based on one-way ANOVA test. Then, the increase in $\mathrm{Pb}^{2+}$ removal is observed with raising ion exchange; however, the loading amounts were decreased during the addition of dosage, resulting from the higher availability of the exchange sites rather than available ions in solution and the ion exchange efficiency was general reduced. Finally, lower $\mathrm{Pb}^{2+}$ ions amounts will there was in

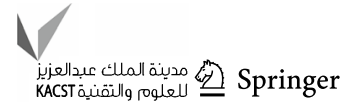




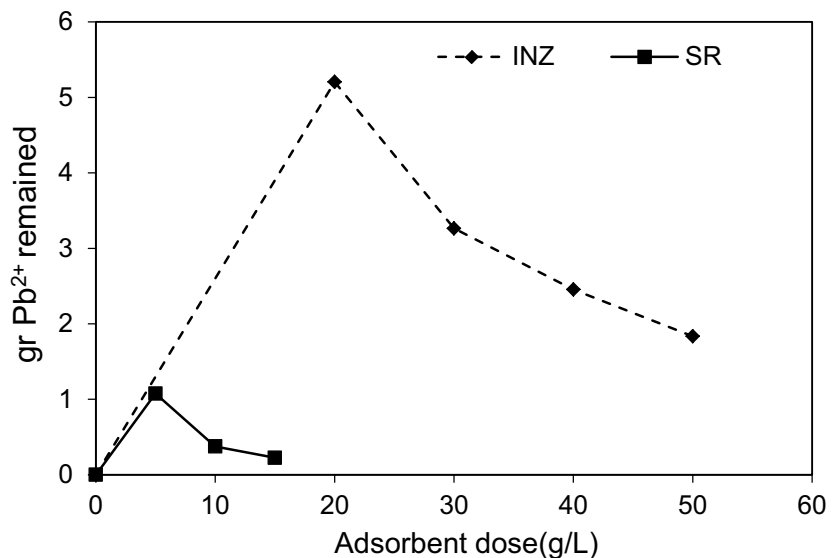

Fig. 5 Influence of adsorbent dose on $\mathrm{Pb}^{2+}$ removal $(\mathrm{pH}=4.5$, initial concentration $=50 \mathrm{mg} / \mathrm{L}$, contact time $=120 \mathrm{~min}$ )

comparison with the available ion exchange sites. This subject is not in an economic way for batch systems. The dispersion of adsorbent particles is good if the adsorbent dosage was low because all active sites on the adsorbent surface are completely disclosed, and they cannot quicken the accessibility of $\mathrm{Pb}^{2+}$ to a large number of the adsorbent active sites (Arshadi et al. 2014). Jamil et al. (2010) reported that the equilibrium concentration in solution phase decreases with increasing the zeolite amount since the fraction of $\mathrm{Pb}^{2+}$ removed from the aqueous phase increases as the sorbent amount is increased (Jamil et al. 2010).

\section{Effect of $\mathrm{pH}$ solution on $\mathrm{Pb}^{2+}$ removal}

The results of the effect of $\mathrm{pH}$ in the range of 3-7 on the removal of $\mathrm{Pb}^{2+}$ are presented in Fig. 6. High removal efficiency was obtained at $\mathrm{pH} 3$ for INZ, while the least removal efficiency of SR was obtained at this $\mathrm{pH}$. But, the changes of removal percentages were very low in the range of 3-7. Oneway ANOVA showed that there was a significant relationship $(p<0.0001)$ between $\mathrm{Pb}^{2+}$ removal percentages with $\mathrm{pH}$ changes. While the Duncan test showed that there was not a significant difference between $\mathrm{pH}$ in the range of 3-7 with $\mathrm{Pb}^{2+}$ removal percentages and for $\mathrm{SR}$, the $\mathrm{pH}$ range of 4-6 is the most suitable $\mathrm{pH}$ for $\mathrm{Pb}^{2+}$ removal percentages of the solution. Kocaoba et al. (2007) study showed that the adsorption percentages of a natural zeolite were increased sharply after $\mathrm{pH} 4$ for $\mathrm{Ni}, \mathrm{Cu}$, and $\mathrm{Cd}$ metals. The $\mathrm{pH} 6$ was chosen as the optimum $\mathrm{pH}$ for all metals for avoiding the precipitation of metals because most of the heavy metal ions tend to form precipitation at $\mathrm{pH}$ higher than 6, which limits this process greatly (Kocaoba et al. 2007). Hamdi and Srasra 2012 showed that the adsorption of phosphate ions by the two clays and the synthetic zeolite samples could be efficiently removed at acidic $\mathrm{pH}$ (between 4 and 6) condition.

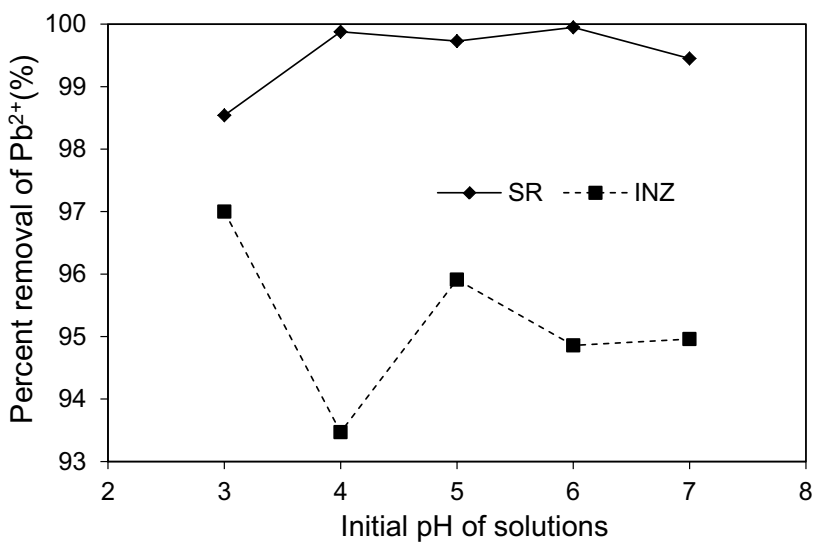

Fig. 6 Influence of $\mathrm{pH}$ changes on $\mathrm{Pb}^{2+}$ removal efficiency (initial concentration $=50 \mathrm{mg} / \mathrm{L}$, contact time $=120 \mathrm{~min}$, adsorbent dose: $\mathrm{INZ}=30 \mathrm{~g} / \mathrm{L}, \mathrm{SR}=10 \mathrm{~g} / \mathrm{L})$

The difference in $\mathrm{pH}$ would have a minimal effect on the surface charge of zeolite (Ponizovsky and Tsadilas 2003). Kim et al. (2013) indicated the removal ranged from $99.9 \%$ when the initial $\mathrm{pH}$ was 4 and $93.5 \%$ when it was 6 (Kim et al. 2013). The results of this study presented that the $\mathrm{Pb}^{2+}$ ions have high removal efficiency in acidic $\mathrm{pH}(\mathrm{pH}=3-5$ and 4-6 for INZ and SR, respectively). These results were endorsed the $\mathrm{Pb}^{2+}$ dominate in solution at acidic $\mathrm{pH}$ (Zhang et al. 2010). Inglezakis et al. (2002) study showed that ion exchange of $\mathrm{Pb}^{2+}$ on natural Clinoptilolite is favorable (Inglezakis et al. 2002).

\section{Effect of INZ particle size}

To achieve the desired particle size of INZ, three sieve granulation sizes were used, and results of this step are displayed in Fig. 7. It can be seen that the sorption of $\mathrm{Pb}^{2+}$ is increased with decreasing particle size. One-way ANOVA showed that there was a significant relationship $(p<0.034)$ between increasing $\mathrm{Pb}^{2+}$ removal percentage with reducing the particle size of INZ. As the sorption is a surface phenomenon, the smaller sorbent sizes have comparatively larger surface areas, and hence, there was higher $\mathrm{Pb}^{2+}$ removal at equilibrium conditions. The results are similar to Bektaş and Kara 2004 and Faghihian et al. (1999) studies. Natural zeolites can be considered as one of the best amendment material for co-composting with sewage sludge taking into account their high efficiency and low cost. Utilization of synthetic zeolite (Zeolite P) as an amendment for compost derived from sewage sludge also demonstrated satisfactory results (Wang and Peng 2010). 


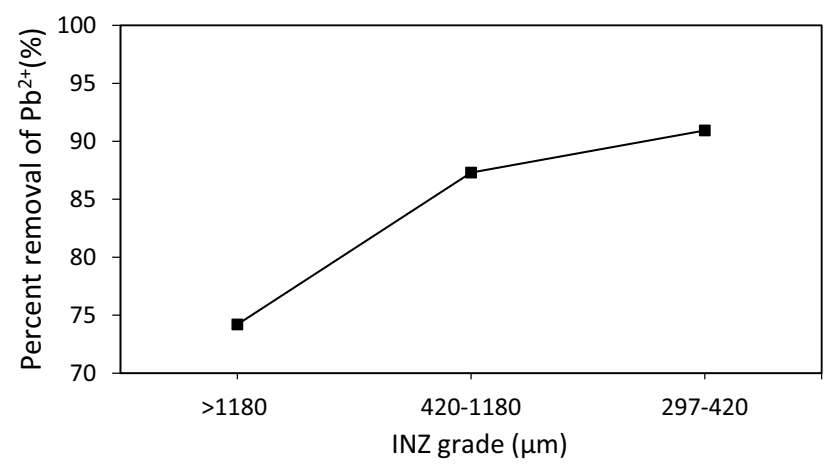

Fig. 7 Effect of particle size for $\mathrm{Pb}^{2+}$ removal capacity of INZ (initial concentration $=50 \mathrm{mg} / \mathrm{L}$, contact time $=120 \mathrm{~min}, \mathrm{pH}=4.5$, adsorbent dose: $\mathrm{INZ}=30 \mathrm{~g} / \mathrm{L}, \mathrm{SR}=10 \mathrm{~g} / \mathrm{L}$ )

\section{Adsorption isotherms}

The adsorption equilibrium data of $\mathrm{Pb}^{2+}$ on INZ and SR adsorbent were fitted by several well-known isotherm models to assess their efficacies. For this matter, ISOFIT was applied to prediction of the adsorption isotherm for $\mathrm{Pb}^{2+}$ removal. Isotherm experiment conducted with $\mathrm{Pb}^{2+}$ concentration of $25-250 \mathrm{mg} / \mathrm{L}$ (interval $50 \mathrm{mg} / \mathrm{L}$ ) by INZ and SR. Water solubility $\left(S_{\mathrm{w}}\right)$ of $\mathrm{Pb}\left(\mathrm{NO}_{3}\right)_{2}$ was estimated $0.53 \mathrm{mg} / \mathrm{L}$ at $\mathrm{pH} 4.5$. Some studies have considered one or more of the supported isotherms in the background of a water and wastewater system. The dual-mode isotherms reflect recently developed models for the adsorption of hydrophobic organic solutes (Matott and Rabideau 2008). Table 3 summarizes some of the diagnostic statistics parameters that computed by ISOFIT and reported in the output file for $\mathrm{Pb}^{2+}$ adsorption by INZ and SR. The AICc values indicate that the Freundlich and Langmuir isotherms expression provides the best fit of $\mathrm{Pb}^{2+}$ adsorption by INZ and SR, respectively. This result is in agreement with various researchers who used Langmuir equation to represent $\mathrm{Pb}^{2+}$ removal by Clinoptilolite (Bektaş and Kara 2004). The agreement of the Langmuir model with the experimental results suggests that a monolayer coverage of $\mathrm{Pb}^{2+}$ ions on the outer surface of INZ and SR. Based on the same study on adsorption of phosphate ions by the two clays and the zeolite samples, the isotherms showed that the zeolite has the highest rate of uptake $(52.9 \mathrm{mg}$ $\mathrm{P} / \mathrm{g}$ ). Equilibrium data of this study were well fitted with Langmuir and Freundlich isotherm (Hamdi and Srasra 2012). For the removal of $\mathrm{Pb}^{2+}$ from solution by a combination of natural zeolite-kaolin-bentonite, the Langmuir isotherm showed the acceptable accuracy in prediction of adsorption data (Salem and Sene 2011). In this study, the best-fitted isotherm for $\mathrm{Pb}^{2+}$ removal by INZ was Freundlich isotherm. The Freundlich isotherm, as an experimental model, can be applied to non-ideal adsorption on

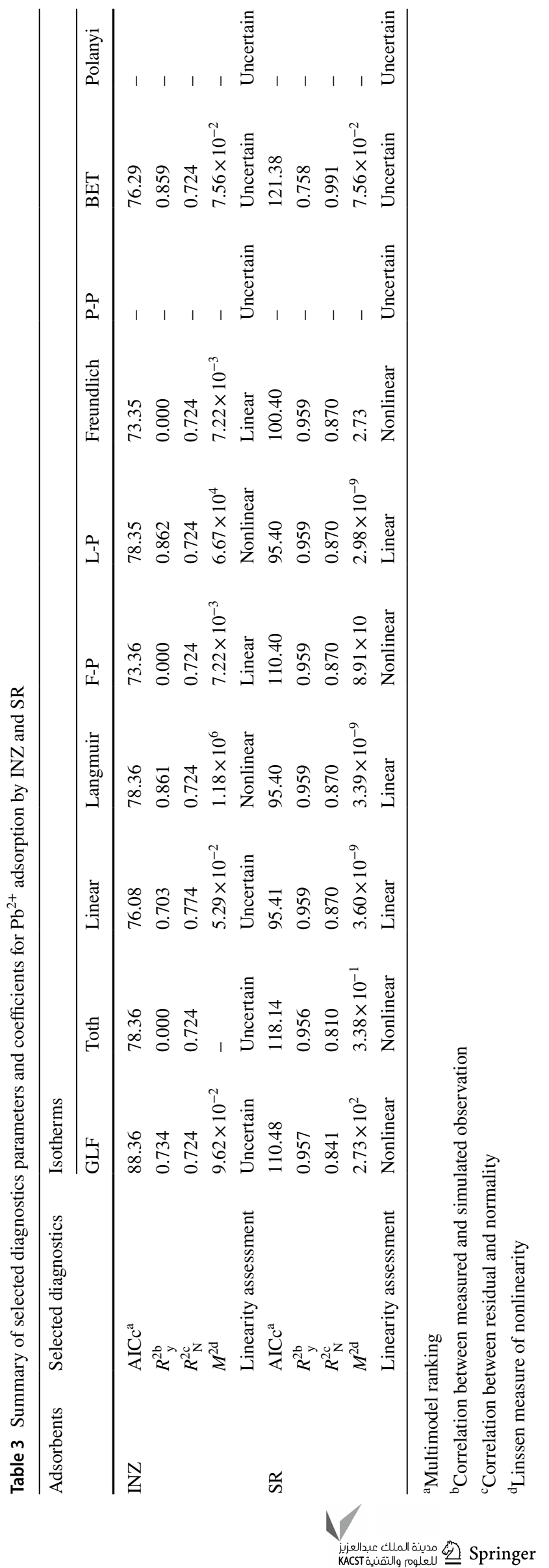


heterogeneous surfaces as well as multilayer sorption. The basic assumption in this model is an exponentially decaying sorption site energy distribution (Anari-Anaraki and Nezamzadeh-Ejhieh 2015).

\section{Conclusion}

In this study, it was concluded that the rates of $\mathrm{Pb}^{2+}$ removal for initial concentrations were rapid at initial times for SR and then kept decreasing gradually. The removal efficiency of two adsorbents was increased with increasing initial $\mathrm{Pb}^{2+}$ concentrations until $50 \mathrm{mg} / \mathrm{L}$. But, the removal efficiency by INZ has been dramatically reduced with increasing initial $\mathrm{Pb}^{2+}$ concentrations in the range of $50-250 \mathrm{mg} / \mathrm{L}$. The removal efficiency by SR has been increased with increasing initial $\mathrm{Pb}^{2+}$ concentrations in this range. The removal efficiency of $\mathrm{Pb}^{2+}$ with increasing contact times was increased firstly for SR and then constant gradually, while it has not increased removal efficiency for INZ. The both of INZ and SR have similar removal efficiency for $\mathrm{Pb}^{2+}$ with increasing adsorbents dosage, and in this the suitable INZ adsorbent dosage was $20 \mathrm{~g} / \mathrm{L}$ and for SR was $5 \mathrm{~g} / \mathrm{L}$. The removal of $\mathrm{Pb}^{2+}$ was increased with $\mathrm{pH}$ increasing; high removal efficiency was obtained at pH 3 and 4-6 for INZ and SR, respectively. Effect of INZ particle size showed that $\mathrm{Pb}^{2+}$ removal was increased with reducing the particle size of INZ. This study indicated that for $\mathrm{Pb}^{2+}$ removal the SR was more efficient than INZ for high concentration solutions; however, in low concentration of $\mathrm{Pb}^{2+}$, the removal efficiency was approximately equal. The Freundlich and Langmuir isotherm models based on ISOFIT software for removal of $\mathrm{Pb}^{2+}$ by INZ and SR showed better correlation with the experimental data, respectively.

Acknowledgements This study is an MSc approved research project (No. 290189) performed at Isfahan University of Medical Sciences, Iran. The authors are thankful for the funding provided by the Department of Environmental Health Engineering and Environment Research Center, Isfahan University of Medical Sciences.

\section{Compliance with ethical standards}

Conflict of interest The authors declare that there is no conflict of interest regarding the publication of this paper.

Open Access This article is licensed under a Creative Commons Attribution 4.0 International License, which permits use, sharing, adaptation, distribution and reproduction in any medium or format, as long as you give appropriate credit to the original author(s) and the source, provide a link to the Creative Commons licence, and indicate if changes were made. The images or other third party material in this article are included in the article's Creative Commons licence, unless indicated otherwise in a credit line to the material. If material is not included in the article's Creative Commons licence and your intended use is not permitted by statutory regulation or exceeds the permitted use, you will need to obtain permission directly from the copyright holder. To view a copy of this licence, visit http://creativecommons.org/licenses/by/4.0/.

\section{References}

Abdel-Halim SH, Shehata AMA, El-Shahat MF (2003) Removal of lead ions from industrial waste water by different types of natural materials. Water Res 37:1678-1683

Ali AAH, El Bishtawi R (1997) Removal of lead and nickel ions using zeolite tuff. J Chem Technol Biotechnol 69:27-34

Anari-Anaraki M, Nezamzadeh-Ejhieh A (2015) Modification of an Iranian clinoptilolite nano-particles by hexadecyltrimethyl ammonium cationic surfactant and dithizone for removal of $\mathrm{Pb}$ (II) from aqueous solution. J Colloid Interface Sci 440:272-281

APHA (2013) Standard methods for the examination of water and wastewater, 22nd edn. American Public Health Association, Washington

Arshadi M, Soleymanzadeh M, Salvacion J, SalimiVahid F (2014) Nanoscale zero-valent iron (NZVI) supported on sineguelas waste for $\mathrm{Pb}$ (II) removal from aqueous solution: kinetics, thermodynamic and mechanism. J Colloid Interface Sci 426:241-251

Barrera-Diaz C, Almaraz-Calderon C, Olguin-Gutierrez MT, RomeroRomo M, Palomar-Pardave M (2005) Cd(II) and Pb(II) separation from aqueous solution using clinoptilolite and Opuntia ectodermis. Environ Technol 26:821-829

Bektaş N, Kara S (2004) Removal of lead from aqueous solutions by natural clinoptilolite: equilibrium and kinetic studies. Sep Purif Technol 39:189-200

Berber-Mendoza MS, Leyva-Ramos R, Alonso-Davila P, FuentesRubio L, Guerrero-Coronado RM (2006) Comparison of isotherms for the ion exchange of $\mathrm{Pb}$ (II) from aqueous solution onto homoionic clinoptilolite. J Colloid Interface Sci 301:40-45

Calvo B et al (2009) Continuous elimination of $\mathrm{Pb}^{2+}, \mathrm{Cu}^{2+}, \mathrm{Zn}^{2+}, \mathrm{H}^{+}$ and $\mathrm{NH}^{4+}$ from acidic waters by ionic exchange on natural zeolites. J Hazard Mater 166:619-627

Castaldi P, Santona L, Enzo S, Melis P (2008) Sorption processes and $\mathrm{XRD}$ analysis of a natural zeolite exchanged with $\mathrm{Pb}\left({ }^{2+}\right), \mathrm{Cd}\left({ }^{2+}\right)$ and $\mathrm{Zn}\left({ }^{2+}\right.$ ) cations. J Hazard Mater 156:428-434

Faghihian H, Marageh MG, Kazemian H (1999) The use of clinoptilolite and its sodium form for removal of radioactive cesium, and strontium from nuclear wastewater and $\mathrm{Pb}^{2+}, \mathrm{Ni}^{2+}, \mathrm{Cd}^{2+}, \mathrm{Ba}^{2+}$ from municipal wastewater. Appl Radiat Isot 50:655-660

Hamdi N, Srasra E (2012) Removal of phosphate ions from aqueous solution using Tunisian clays minerals and synthetic zeolite. J Environ Sci 24:617-623

Hamidpour M, Kalbasi M, Afyuni M, Shariatmadari H, Holm PE, Hansen HCB (2010) Sorption hysteresis of Cd(II) and Pb(II) on natural zeolite and bentonite. J Hazard Mater 181:686-691

Hesami F, Bina B, Ebrahimi A, Amin MM (2013) Arsenic removal by coagulation using ferric chloride and chitosan from water. Int $\mathrm{J}$ Environ Health Eng 2:17

Hwang SY, Yoo ES, Im SS (2011) Effects of TS-1 zeolite structures on physical properties and enzymatic degradation of poly(butylene succinate) (PBS)/TS-1 zeolite hybrid composites. Polymer 52:965-975

Inglezakis V, Loizidou M, Grigoropoulou H (2002) Equilibrium and kinetic ion exchange studies of $\mathrm{Pb}^{2+}, \mathrm{Cr}^{3+}, \mathrm{Fe}^{3+}$ and $\mathrm{Cu}^{2+}$ on natural clinoptilolite. Water Res 36:2784-2792

Inglezakis VJ, Loizidou MD, Grigoropoulou HP (2003) Ion exchange of $\left.\mathrm{Pb}\left({ }^{2+}\right), \mathrm{Cu}\left({ }^{2+}\right), \mathrm{Fe}^{(3+}\right)$, and $\mathrm{Cr}\left({ }^{3+}\right)$ on natural clinoptilolite: selectivity determination and influence of acidity on metal uptake. J Colloid Interface Sci 261:49-54 
Jamil TS, Ibrahim HS, El-Maksoud IA, El-Wakeel S (2010) Application of zeolite prepared from Egyptian kaolin for removal of heavy metals: I. Optimum conditions. Desalination 258:34-40

Jha VK, Matsuda M, Miyake M (2008) Sorption properties of the activated carbon-zeolite composite prepared from coal fly ash for $\mathrm{Ni}^{2+}, \mathrm{Cu}^{2+}, \mathrm{Cd}^{2+}$ and $\mathrm{Pb}^{2+}$. J Hazard Mater 160:148-153

Kim SA et al (2013) Removal of $\mathrm{Pb}$ (II) from aqueous solution by a zeolite-nanoscale zero-valent iron composite. Chem Eng J 217:54-60

Kocaoba S, Orhan Y, Akyüz T (2007) Kinetics and equilibrium studies of heavy metal ions removal by use of natural zeolite. Desalination 214:1-10

Mahdavi M, Amin MM, Mahvi AH, Pourzamani H, Ebrahimi A (2017) Metals, heavy metals and microorganism removal from spent filter backwash water by hybrid coagulation-UF processes. J Water Reuse Desalination 8(2):225-233

Matott LS, Rabideau AJ (2008) ISOFIT — a program for fitting sorption isotherms to experimental data. Environ Model Softw 23:670-676

Mier MV, Callejas RL, Gehr R, Cisneros BEJ, Alvarez PJ (2001) Heavy metal removal with Mexican clinoptilolite: multi-component ionic exchange. Water Res 35:373-378

Moazeni M, Ebrahimi A, Rafiei N, Pourzamani HR (2017) Removal of lead ions from aqueous solution by nano zero-valent iron (nZVI). Health Scope 6:1-7

Mozgawa W, Krol M, Pichor W (2009) Use of clinoptilolite for the immobilization of heavy metal ions and preparation of autoclaved building composites. J Hazard Mater 168:1482-1489

Ponizovsky AA, Tsadilas CD (2003) Lead (II) retention by Alfisol and clinoptilolite: cation balance and $\mathrm{pH}$ effect. Geoderma $115: 303-312$
Salem A, Sene RA (2011) Removal of lead from solution by combination of natural zeolite-kaolin-bentonite as a new low-cost adsorbent. Chem Eng J 174:619-628

Sawyer CN, McCarty PL, Parkin GF (2003) Chemistry for environmental engineering and science. McGraw-Hill, Boston

Suh JH, Kim DS (2000) Comparison of different sorbents (inorganic and biological) for the removal of $\mathrm{Pb}^{2+}$ from aqueous solutions. J Chem Technol Biotechnol 75:279-284

Ulmanu M, Segarceanu T, Vasiliu C, Anger I (1996) Removal of copper from dilute aqueous solutions by adsorbent and ion exchange materials. Spec Publ-Roy Soc Chem 182:151-159

Ulmanu M, Marañón E, Fernandez Y, Castrillon L, Anger I, Dumitriu D (2003) Removal of copper and cadmium ions from diluted aqueous solutions by low cost and waste material adsorbents. Water Air Soil Pollut 142:357-373

Wang S, Peng Y (2010) Natural zeolites as effective adsorbents in water and wastewater treatment. Chem Eng J 156:11-24

Yang X, Yang S, Yang S, Hu J, Tan X, Wang X (2011) Effect of pH, ionic strength and temperature on sorption of $\mathrm{Pb}(\mathrm{II})$ on NKF-6 zeolite studied by batch technique. Chem Eng J 168(1):86-93

Zhang X, Lin S, Lu X-Q, Chen Z-1 (2010) Removal of Pb(II) from water using synthesized kaolin supported nanoscale zero-valent iron. Chem Eng J 163:243-248

Publisher's Note Springer Nature remains neutral with regard to jurisdictional claims in published maps and institutional affiliations. 